\title{
Nature Activities in Urban Parks to Encourage Curiosity and Scientific Problem-Solving Ability in Kindergarteners
}

\author{
Eun-Jin Kim ${ }^{1}$ and Chang-Duck Koo ${ }^{2 *}$ \\ ${ }^{1}$ Graduate Department of Forest Therapy, Chungbuk National University, Cheongju 28644, Korea \\ ${ }^{2}$ Department of Foresty, Chungbuk National University, Cheongju 28644, Korea
}

\section{ABSTRACT}

This study was conducted based on the fact that children in institutions for early childhood education located in cities lack the opportunity to experience nature. Therefore, urban parks are where it is possible to observe nature and natural environment, through which we examined the effects of nature activities on kindergarten children's curiosity and scientific problem-solving ability. The subjects of this study were 5-years old kindergarten children in attending public kindergartens in Cheonan and Asan and 42 children were randomly selected. The pretest and posttest were conducted on curiosity and scientific problem-solving ability before and after nature activities. The results showed that nature activities in urban parks had significant effects on improvement of kindergarten children's curiosity and scientific problem-solving ability ( $p\langle .05)$. Therefore, nature activities in urban parks had positive effects on preference for unknown and exploratory behavior, which are sub-factors of kindergarten children's curiosity. Nature activities also had positive effects on discovery and statement of the problem, creation and application of ideas, and conclusion to problem solving.

Keywords: natural environment, nature experience, science education

\section{Introduction}

In the 21 st-century modern society, rapid changes in science and technology cause scientific understanding and literacy to affect the quality of life for people, which is why they need education to have enough scientific experience since childhood. Therefore, it is necessary to provide opportunities to receive science education through which learners with scientific literacy discover the joy of participating and exploring in the courses of education (Kim, 2013).

Early childhood science education has great educational effects when learners are to approach and discover knowledge through enthusiastic and active activities, rather than when knowledge is passively delivered to learners for memorization (Kim and Kim, 2004). The goal of nature inquiry set by the Ministry of Education, Science and
Technology(2013) is to have preschool children develop an inquiring attitude with curiosity about surrounding objects or natural phenomenon, logically and mathematically solve problems faced in everyday life, and nurture the basic mathematical and scientific thinking ability and attitude by exploring objects, life and natural phenomenon in which they are interested.

However, at institutions for early childhood education located in cities, preschool children face difficulty in approaching nature because there is insufficient space to experience the vitality of nature and they cannot visit natural areas like the forest or river freely (Yoon, 2008). Many preschool teachers provide science education just for show through demonstrations of experiments or teach scientific phenomena and laws by merely explaining them, rather than structuring knowledge through learners' experience

Received: September 11, 2019, Revised: September 25, 2019, Accepted: October 8, 2019

First author: Eun-Jin Kim, ann17@hanmail.net, (1) https://orcid.org/0000-0003-2602-904X

*Corresponding author: Chang-Duk Koo, koocdm@chungbuk.ac.or, (1D https://orcid.org/0000-0001-9508-8858 
(Kwak, 2015). Therefore, there is a need for value-oriented science education that respects nature and humanity by regaining the essentiality and purpose of science (Seo, 2018).

Other studies prove that a place outside the classroom is the base of activities as well as integrated and stimulating learning environment that provides opportunities for preschool children to have emotional experience and work freely. Thus, even young children can more easily realize what belongs to nature and reconstruct their emotions, obtain information at their own pace, attempt different learning styles, and acquire learning opportunities different from those in the classroom (Yildirim and Özyilmaz Akamca, 2017).

The following shows the results of previous studies on how the natural environment affects development of preschool children. Direct and continuous experience of nature in a familiar environment performs a critical role in physical, emotional and sustainable development of preschool children (Kellert, 2005), and proximity and daily exposure to the natural environment enhance the ability to focus and improve preschool children's cognitive skills (Wells, 2000). Discovery in the natural environment affects meaningful learning and enables development of emotional connection about the environment. It is important to promote respect for valuable things, attitudes toward caring, lifestyles, and sustainable behaviors (Bento and Dias, 2017). Forest, which is a typical natural environment, provides the ability and opportunity for preschool children to satisfy their curiosity, solve problems, and discover and create new things by stimulating the instincts of expression and creation inherent in their nature (Cho, 2005). Kim (2010) refers to ecological education in early childhood as a set of activities based on life in which preschool children solve problems by planning and playing what they want to do in pairs or groups, and learn and realize certain things on their own.

Curiosity indicates the attitude of showing interest in and exploring many questions that arise in the process of comparative observation, which refers to the preference for unknown to find out more about what they do not know, and exploratory activities to observe and handle new objects or situations (Kim, 2016). In this study, it refers to a set of activities through which preschool children show interest in and explore surrounding objects and natural phenomenon in the process of carrying out nature activities at urban parks, and its sub-categories are preference for unknown and exploratory activities (Lee, 2001) defined as follows. Preference for unknown indicates the need or desire to know more about things that are uncertain or unknown; exploratory activities indicate the process of observing, handling and questioning new objects or situations.

Scientific problem-solving ability is divided into the stage of discovering and stating science-related problems, the stage of scientifically suggesting and applying ideas for problem solving, and the stage of making conclusions about scientific problem solving (Yoon, 2012). Each stage can be defined as follows. Discovery and statement of the problem includes paying attention to the teacher's problem posing, showing interest in the problem, and describing the problem in one's own words. Suggestion and application of ideas for the problem includes suggesting one's own ideas and applying ideas. Conclusion about problem solving includes making conclusions based on results.

This study carried out nature activities in the walkway, stream, urban park, and urban forest near the kindergarten that are close to everyday life and relatively accessible, and where it is possible to observe nature and natural phenomena. Through these activities, preschool children start from merely having curiosity about the objects or phenomena they experienced and go on to constantly find what they are curious about and try finding out more specifically about it to satisfy their curiosity themselves. This study was conducted to examine whether nature activities in urban parks have effects on preschool children's curiosity and improvement of scientific problem-solving ability.

\section{Research Methods}

\section{Subjects}

The subjects of this study are 42 randomly selected preschool children aged 5, attending the kindergarten attached to Y Elementary school and the kindergarten attached to C Elementary School located in Asan and Cheonan, Chungcheongnam-do. The experiment was conducted on the experimental group and control group with different education environments depending on whether there is an 
ecological stream and urban park based on the forest, which is a natural environment, near the kindergarten. The teachers for the two groups have at least 20 years of experience, and the kindergarten is operated in the full-day curriculum for all children based on the Nuri Curriculum at the national level. Table 1 shows the distribution of the children's age and gender.

\section{Measurement tools}

\section{Curiosity test}

This study used the curiosity test modified and improved by Lee (2001). The testing tool of preference for unknown was first designed by Smock and Holt (1962), and Handerson and Moore (1979) presented that the reliability is .74 through repeated test. Exploratory behavior was tested using the Curiosity Drawer Box first designed by McReynolds et al. (1961). The reliability of the exploratory behavior test showed a range of .80-.99 among the testers (Ko and Cho, 2015), and the reliability (Cronbach's $\alpha$ ) in this study was .79.

The tests for the sub-categories of curiosity such as preference for unknown and exploratory behavior are as follows.

Table 1. Age and gender characteristics of the subjects

\begin{tabular}{lcccc}
\hline \multirow{2}{*}{ Group } & $\mathrm{n}$ & \multicolumn{2}{c}{ Gender } & \multirow{2}{*}{$\begin{array}{c}\text { Average age } \\
\text { in months }\end{array}$} \\
\cline { 3 - 4 } & & Male & Female & 75.00 \\
Experimental & 21 & 9 & 12 & 76.05 \\
Control & 21 & 11 & 10 & 75.53 \\
Total & 42 & 20 & 22 & \\
\hline
\end{tabular}

The test of preference for unknown is comprised of eight pairs ( 16 pieces) of toys, a $30 \times 50 \mathrm{~cm}$ wooden board to hide the toys, and the questionnaire. The test of exploratory behavior is comprised of 18 toys, a $30 \mathrm{~cm} \times 60 \mathrm{~cm} \times 12 \mathrm{~cm}$ wooden box with 18 drawers, and the questionnaire.

The curiosity testing methods are as shown in Table 2.

The scoring method of the preference for unknown, which is a sub-category of the curiosity test, is to give 1 point for each time the child chooses the toy hidden behind the board, and 0 point for each time the child chooses the toy he or she can see. Each child can receive the score of 0 to 8 points. The maximum testing time for the exploratory behavior test (Curiosity Drawer Box) is 10 minutes. It is obtained by adding up the scores for the number of questions related to the toy, number of other operations, playing time, and number of toys taken out from the drawers. The score range for the exploratory behavior test is $0-20$ points depending on the number of questions related to the toy, 0-20 points depending on the number of other operations, 0-20 points depending on the playing time, and $0-18$ points depending on the number of times a toy is taken out from the drawers. The total score range for the exploratory behavior test is 0-78 points.

\section{Scientific problem-solving ability test}

The scientific problem-solving ability test used in this study was first designed by Tegano et al. (1989) and modified and improved by Moon (2000) (Hwang et al., 2012). Reliability of the test is presented as .74 (Cho and Kim, 2013), the reliability (Cronbach's $\alpha$ ) in this study was .83 .

Table 2. Test of curiosity in children

\begin{tabular}{|c|c|c|c|c|}
\hline Subca & \multicolumn{2}{|c|}{ Inspection tool } & & \\
\hline \multirow[t]{2}{*}{$\begin{array}{l}\text { Preference for } \\
\text { unknown }\end{array}$} & \multirow{2}{*}{\multicolumn{2}{|c|}{ (Wooden board) }} & $\begin{array}{l}\text { 1. The examiner prepares a wooden board and } 16 \text { toys. } \\
\text { 2. Eight toys are placed in front of children and eight toys are } \\
\text { placed behind wooden board. }\end{array}$ & \multirow{2}{*}{$\begin{array}{l}\text { A home, a doll, a car, a bike, keys, a } \\
\text { necklace, a duck, a frog, a truck, a } \\
\text { train, a clock, a robot, oil, a syringe, } \\
\text { a compass, a cellphone }\end{array}$} \\
\hline & & & 3. The examiner asked which one the child wants to play with & \\
\hline \multirow{5}{*}{$\begin{array}{c}\text { Exploratory } \\
\text { behavior }\end{array}$} & & & \multirow{5}{*}{$\begin{array}{l}\text { 1. The examiner prepares the drawer box with } 18 \text { drawers } \\
\text { containing one toy per a drawer. } \\
\text { 2. The examiner tells the child to open the drawer and play } \\
\text { freely. } \\
\text { 3. The child explores freely and researcher measures child's } \\
\text { search behavior. }\end{array}$} & \multirow{5}{*}{$\begin{array}{l}\text { Scissors, a thermometer, a battery, a } \\
\text { chicken bone, a hospital car, a doll, } \\
\text { a robot, a horse, a magnet, a bottle } \\
\text { opener, a lock, a music box, a fire } \\
\text { truck, a barrette, a toy gun, a } \\
\text { syringe, a guitar, an elephant }\end{array}$} \\
\hline & . & • & & \\
\hline & . & . & & \\
\hline & & . & & \\
\hline & \multicolumn{2}{|c|}{ (Curiosity drawer box) } & & \\
\hline
\end{tabular}


Table 3. Test of scientific problem-solving ability in children

\begin{tabular}{|c|c|c|}
\hline Subcategory & Step & Method \\
\hline \multirow{3}{*}{$\begin{array}{l}\text { Discovery and } \\
\text { statement of } \\
\text { problem }\end{array}$} & Pay attention to the teacher's problem presentation & $\begin{array}{l}\text { - The examiner releases the data and tells a child, "There are many } \\
\text { things here. Can you tell me what's going on?" }\end{array}$ \\
\hline & Interest in the problem & - Observing the child's behavior \\
\hline & Can you explain the problem in your own words? & $\begin{array}{l}\text { - The examiner observes the child's response after asking the child } \\
\text { "What do you want to do with these here?" }\end{array}$ \\
\hline \multirow{2}{*}{$\begin{array}{l}\text { Creating and } \\
\text { applying ideas to } \\
\text { problem }\end{array}$} & Creating ideas & $\begin{array}{l}\text { The examiner asks the child to think and talk about how he or she } \\
\text { would like to work with the data given and then observes the } \\
\text { child's response. }\end{array}$ \\
\hline & The process of applying ideas & $\begin{array}{l}\text { - The examiner observes whether the child applies the method } \\
\text { proposed. }\end{array}$ \\
\hline $\begin{array}{l}\text { Conclusion to } \\
\text { problem-solving }\end{array}$ & Conclusion based on results & $\begin{array}{l}\text { - The examiner asks the child about the outcome of the activity } \\
\text { after the activity and observes the child's response. }\end{array}$ \\
\hline
\end{tabular}

The scientific problem-solving ability test is comprised of problem-solving ability pretest activities, problem-solving ability posttest activities, and problem-solving process observation assessment through which the problem-solving process of the children can be observed. The testing methods for scientific problem-solving ability are as shown in Table 3.

The scoring method of preschool children's scientific problem-solving ability is to give 3 points if the problem-solving level is very high, 2 points if it is high, 1 point if it is average, and 0 point if it is low, all of which are added to come up with the total score of scientific problem-solving ability. The score range is $0-18$ points.

\section{Methods}

This study carried out nature activities to improve preschool children's curiosity and scientific problem-solving ability. The experimental group, comprised of 21 children from the kindergarten attached to Y Elementary School, participated in nature activities with their homeroom teacher, through which the children discovered, explored and experienced soil, rocks, water, grass, trees and insects that are easily found near the walkway, stream, urban park and urban forest around Jisan Park and Yonggok Park in Asan. The control group, comprised of children from the kindergarten attached to C Elementary School, participated in science education activities with their homeroom teacher based on the Nuri Curriculum for age 5 in the classroom.
The life topics of the activities carried out in this study were the same: Korea, many countries of the world, autumn and animals/plants, environment and life. The research was conducted in the order of pretest, experiment and posttest. There was one week of pretest, 10 weeks of experiment (50 minutes per sessions, total 10 sessions) and one week of posttest, and the period was from September 27 to December 14, 2018. The nature activities of the experimental group and the scientific activities of the control group are as shown in Tables 4 and 5 .

\section{Data processing}

This study used SPSS 18.0 Program for analysis to examine the effects of nature activities in urban parks on preschool children's curiosity and scientific problem-solving ability. The nonparametric test is conducted because the collected data do not follow normal distribution. The Mann-Whitney U Test was performed to test the homogeneity between the two groups. The same test was also performed on the data measured in the posttest to analyze the changes between the two groups. The Wilcoxon Signed-Ranks Test was performed to compare the pretest-posttest results of the experimental group. 
Table 4. Nature activities for experimental group

\begin{tabular}{|c|c|c|c|}
\hline $\begin{array}{c}\text { Time } \\
\text { (Week) }\end{array}$ & Topic & Program contents & Activities \\
\hline 1 & Korea & Pine cone hygrometer play & $\begin{array}{l}\text { Listening to the pine cone sounds, sprinkling glitter on the } \\
\text { pine cone, observing }\end{array}$ \\
\hline 2 & Korea & Spiderweb & Learning about webs, exploring, making spiderweb with yarn \\
\hline 3 & Korea & Explore different leaves & Becoming a caterpillar, leaf classification, tree decoration \\
\hline 4 & Many countries around the world & Mandala in the forest & Collecting nature, classifying natural objects, creating a mandala \\
\hline 5 & Many countries around the world & 10 minutes around the world & $\begin{array}{l}\text { Discovering the world's climate in forests (Desert and } \\
\text { wetland, grassland, rainforest, mountain area, etc.) }\end{array}$ \\
\hline 6 & Autumn, animal and plants & Ladybugs, a garden friend & $\begin{array}{l}\text { Listening to insect stories, playing games, understanding } \\
\text { symbiosis }\end{array}$ \\
\hline 7 & Autumn, animal and plants & Smithy play & Making toys using natural materials \\
\hline 8 & Autumn, animal and plants & Winter preparation of squirrel & Learning about winter squirrels \\
\hline 9 & Environment and life & Play in the woods & $\begin{array}{l}\text { Mimicking bird sounds, stone sounds, leaves sounds, etc., } \\
\text { exploring forest sounds }\end{array}$ \\
\hline 10 & Environment and life & Mud play & $\begin{array}{l}\text { Observing soil and water, feeling and touching mud, making } \\
\text { mud work }\end{array}$ \\
\hline
\end{tabular}

Table 5. Scientific activities for control group

\begin{tabular}{|c|c|c|c|}
\hline $\begin{array}{l}\text { Time } \\
\text { (Week) }\end{array}$ & Topic & Program contents & Activities \\
\hline 1 & Korea & What is it used for? & Learning how to use old things \\
\hline 2 & Korea & Phases of the moon & $\begin{array}{l}\text { Watching video about the phases of the moon, } \\
\text { understanding a changing cycle }\end{array}$ \\
\hline 3 & Korea & Beautiful color of our clothes & Exploring Hanbok's colors and dyeing fabric \\
\hline 4 & Many countries around the world & Make a sundial & $\begin{array}{l}\text { Understanding the principle of the sundial, the connections } \\
\text { between the changes in shadow and the passage of time }\end{array}$ \\
\hline 5 & Many countries around the world & $\begin{array}{l}\text { The invention of the clock that } \\
\text { made the world convenient }\end{array}$ & Comparing and observing different kind of watches \\
\hline 6 & Autumn, animal and plants & Explore autumn fruits & $\begin{array}{l}\text { Observing shapes and colors of fruits that ripe in autumn } \\
\text { and their seeds }\end{array}$ \\
\hline 7 & Autumn, animal and plants & Tree insects & $\begin{array}{l}\text { Watching insects and learning about the characteristics of } \\
\text { insects }\end{array}$ \\
\hline 8 & Autumn, animal and plants & Find out the temperature of the day & $\begin{array}{l}\text { Comparing summer and autumn weather, reading a } \\
\text { thermometer, learning about diurnal temperature variation }\end{array}$ \\
\hline 9 & Environment and life & Find the air & $\begin{array}{l}\text { Learning about the characteristics of air, finding objects } \\
\text { that contain air }\end{array}$ \\
\hline 10 & Environment and life & Nature of light & Finding light source around me, knowing the benefits of light \\
\hline
\end{tabular}

\section{Results and Discussion}

\section{Results of the homogeneity test of the experimental group and control group}

In Table 6, the Mann-Whitney U Test was conducted with the pretest results of the two groups. The results showed that, regarding sub-factors of curiosity, the significance probability between the two groups for preference for unknown is $(\mathrm{z}=-0.104, p>.05)$, and the significance probability for exploratory behavior is $(\mathrm{z}=-0.104, p>.05)$. There is no statistically significant difference between the two groups for curiosity and thus they are approved as sim- 
ilar groups. Regarding sub-factors of scientific problem-solving ability, the significance probability for discovery and statement of the problem is $(\mathrm{z}=-0.613, p>.05)$, the significance probability for application of ideas is $(\mathrm{z}=-0.351$, $p>.05$ ), and the significance probability for conclusion about problem solving is ( $\mathrm{z}=-0.185, p>.05)$, showing no statistically significant difference between the two groups. As a result of the homogeneity testing for the pretest of the two groups, the significance probability had no statistically significant difference and thus the two groups are approved as similar groups, thereby suitable for research.

\section{Posttest comparison of the experimental group and control group}

As shown in Table 7, the Mann-Whitney U Test was conducted to determine the posttest results of the ex- perimental group and control group to examine the effects of nature activities in urban parks on preschool children's curiosity and scientific problem-solving ability.

In Table 7, the Mann-Whitney U Test was conducted with the posttest results of the two groups. The results showed that the significance probability between the two groups for preference for unknown that is a sub-factor of curiosity $(\mathrm{z}=-1.565, p>.05)$ did not have a difference, thereby showing no statistically significant difference between the two groups, whereas the significance probability for exploratory behavior that is a sub-factor of curiosity $(\mathrm{z}=3.397$, $p<.05)$ showed a significant difference. As for sub-factors of scientific problem-solving ability, the significance probability for discovery and statement of the problem $(\mathrm{z}=-2.067$, $p<.05$ ), the significance probability for application of ideas $(\mathrm{z}=-2.067, p<.05)$, and the significance probability for conclusion about problem solving $(\mathrm{z}=-2.340, p<.05)$ all

Table 6. Homogeneity test for curiosity and scientific problem-solving ability

\begin{tabular}{|c|c|c|c|c|c|c|c|}
\hline Variable & Subcategory & Group & $\mathrm{n}$ & Mean Rank & Sum of Ranks & $z$ & $p$ \\
\hline \multirow{4}{*}{ Curiosity } & \multirow{2}{*}{ Unknown preference } & Experimental & 21 & 21.69 & 455.50 & \multirow{2}{*}{-0.104} & \multirow{2}{*}{.918} \\
\hline & & Control & 21 & 21.31 & 447.50 & & \\
\hline & \multirow{2}{*}{ Search behavior } & Experimental & 21 & 20.60 & 432.50 & \multirow{2}{*}{-0.478} & \multirow{2}{*}{.632} \\
\hline & & Control & 21 & 22.40 & 470.50 & & \\
\hline \multirow{6}{*}{$\begin{array}{c}\text { Scientific } \\
\text { problem- } \\
\text { solving } \\
\text { ability }\end{array}$} & \multirow{2}{*}{ Discovery and statement of problem } & Experimental & 21 & 22.64 & 475.50 & \multirow{2}{*}{-0.613} & \multirow{2}{*}{.540} \\
\hline & & Control & 21 & 20.36 & 427.50 & & \\
\hline & \multirow{2}{*}{ Creating and applying ideas to problem } & Experimental & 21 & 20.86 & 438.00 & \multirow{2}{*}{-0.351} & \multirow{2}{*}{.725} \\
\hline & & Control & 21 & 22.14 & 465.00 & & \\
\hline & \multirow{2}{*}{ Conclusion to problem-solving } & Experimental & 21 & 21.17 & 444.50 & \multirow{2}{*}{-0.185} & \multirow{2}{*}{.853} \\
\hline & & Control & 21 & 21.83 & 458.50 & & \\
\hline
\end{tabular}

Table 7. Post-test comparison of curiosity and scientific problem-solving ability between groups

\begin{tabular}{|c|c|c|c|c|c|c|c|}
\hline Variable & Subcategory & Group & $\mathrm{n}$ & Mean Rank & Sum of Ranks & $z$ & $p$ \\
\hline \multirow{4}{*}{ Curiosity } & \multirow{2}{*}{ Unknown preference } & Experimental & 21 & 24.33 & 511.00 & \multirow{2}{*}{-1.565} & \multirow{2}{*}{.118} \\
\hline & & Control & 21 & 18.67 & 392.00 & & \\
\hline & \multirow{2}{*}{ Search behavior } & Experimental & 21 & 27.93 & 586.50 & \multirow{2}{*}{-3.397} & \multirow{2}{*}{.001} \\
\hline & & Control & 21 & 15.07 & 316.50 & & \\
\hline \multirow{6}{*}{$\begin{array}{c}\text { Scientific } \\
\text { problem- } \\
\text { solving } \\
\text { ability }\end{array}$} & \multirow{2}{*}{ Discovery and statement of problem } & Experimental & 21 & 25.36 & 532.50 & \multirow{2}{*}{-2.067} & \multirow{2}{*}{.039} \\
\hline & & Control & 21 & 17.64 & 370.50 & & \\
\hline & \multirow{2}{*}{ Creating and applying ideas to problem } & Experimental & 21 & 25.81 & 542.00 & \multirow{2}{*}{-2.340} & \multirow{2}{*}{.019} \\
\hline & & Control & 21 & 17.19 & 361.00 & & \\
\hline & \multirow{2}{*}{ Conclusion to problem-solving } & Experimental & 21 & 25.64 & 538.50 & \multirow{2}{*}{-2.340} & \multirow{2}{*}{.017} \\
\hline & & Control & 21 & 17.36 & 364.50 & & \\
\hline
\end{tabular}


showed a significant difference between the two groups.

\section{Comparison of the pretest-posttest results of the experimental group}

\section{Comparison of the pretest-posttest results for preference for unknown as a sub-factor of curiosity}

As a result of analyzing the pretest-posttest results for preference for unknown as a sub-factor of curiosity in the experimental group as shown in Table 8, the significance probability is $(\mathrm{z}=-2.114, p<.05)$, thereby showing a significant difference. Thus, nature activities in urban parks had positive effects on preference for unknown, which is a sub-factor of preschool children's curiosity.

\section{Comparison of the pretest-posttest results for exploratory behavior as a sub-factor of curiosity}

As a result of analyzing the pretest-posttest results for exploratory behavior as a sub-factor of curiosity in the experimental group as shown in Table 9, the significance probability is $(\mathrm{z}=-4.015, p<.05)$, thereby showing a significant difference. Thus, nature activities in urban parks had positive effects on exploratory behavior, which is a sub-factor of preschool children's curiosity.

\section{Comparison of the pretest-posttest results for discovery and statement of the problem as a sub-factor of scientific problem-solving ability}

As a result of analyzing the pretest-posttest results for discovery and statement of the problem as a sub-factor of scientific problem-solving ability in the experimental group as shown in Table 10 , the significance probability is $(\mathrm{z}=$ $-4.053, p<.05)$, thereby showing a significant difference. Thus, nature activities in urban parks had positive effects on discovery and statement of the problem, which is a sub-factor of preschool children's scientific problem-solving ability.

Table 8. Differences between pre and post-test scores for preference for unknown

\begin{tabular}{cccccc}
\hline Ranks & $\mathrm{n}$ & Mean Rank & Sum of Ranks & $\mathrm{z}$ & \\
\hline Negative & $6^{\mathrm{a}}$ & 7.50 & 45.00 & 145.00 & -2.114 \\
Positive & $13^{\mathrm{b}}$ & 11.15 & & \\
Equal & $2^{\mathrm{c}}$ & & & \\
Total & 21 & & & \\
\hline
\end{tabular}

${ }^{\mathrm{a}}$ Post-test scores $<$ Pre-test scores, ${ }^{\mathrm{b}}$ Post-test scores $>$ Pre-test scores, ${ }^{\mathrm{c}}$ Post-test scores $=$ Pre-test scores.

Table 9. Differences between pre and post-test scores for exploratory behavior

\begin{tabular}{cccccc}
\hline Ranks & $\mathrm{n}$ & Mean Rank & Sum of Ranks & $\mathrm{z}$ & $p$ \\
\hline Negative & $0^{\mathrm{a}}$ & 0.00 & 0.00 & -4.015 & .000 \\
Positive & $21^{\mathrm{b}}$ & 11.00 & 231.00 & & \\
Equal & $0^{\mathrm{c}}$ & & & \\
Total & 21 & & & \\
\hline
\end{tabular}

${ }^{\mathrm{a}}$ Post-test scores $<$ Pre-test scores, ${ }^{\mathrm{b}}$ Post-test scores $>$ Pre-test scores, ${ }^{\mathrm{c}}$ Post-test scores $=$ Pre-test scores.

Table 10. Differences between pre and post-test scores for discovery and statement of problem

\begin{tabular}{cccccc}
\hline Ranks & $\mathrm{n}$ & Mean Rank & Sum of Ranks & $\mathrm{z}$ & \multicolumn{2}{c}{-0.00} & \\
\hline Negative & $0^{\mathrm{a}}$ & 0.00 & 210.00 & & \\
Positive & $20^{\mathrm{b}}$ & 10.50 & & \\
Equal & $1^{\mathrm{c}}$ & & & \\
Total & 21 & & & \\
\hline
\end{tabular}

${ }^{\mathrm{a}}$ Post-test scores $<$ Pre-test scores, ${ }^{\mathrm{b}}$ Post-test scores $>$ Pre-test scores, ${ }^{\mathrm{c}}$ Post-test scores $=$ Pre-test scores. 


\section{Comparison of the pretest-posttest results for} suggestion and application of ideas for the problem as a sub-factor of scientific problem-solving ability

As a result of analyzing the pretest-posttest results for suggestion and application of ideas for the problem as a sub-factor of scientific problem-solving ability in the experimental group as shown in Table 11, the significance probability is $(\mathrm{z}=-4.041, p<.05)$, thereby showing a significant difference. Thus, nature activities in urban parks had positive effects on suggestion and application of ideas for the problem, which is a sub-factor of preschool children's scientific problem-solving ability.

\section{Comparison of the pretest-posttest results for conclusion about problem solving as a sub-factor of scientific problem-solving ability}

As a result of analyzing the pretest-posttest results for conclusion about problem solving as a sub-factor of scientific problem-solving ability in the experimental group as shown in Table 12, the significance probability is $(z=-3.358$, $p<.05$ ), thereby showing a significant difference. Thus, nature activities in urban parks had positive effects on conclusion about problem solving, which is a sub-factor of preschool children's scientific problem-solving ability.

\section{Discussions}

The following discussions can be made based on the results of this study. First, nature activities in urban parks have positive effects on preference for unknown and exploratory behavior that are sub-factors of preschool children's curiosity. Natural objects discovered and observed through nature activities stimulate curiosity about the joy of exploration, many uncertainties, extremely unfamiliar things, and very complicated things, thereby motivating children to find out about them (Borowske, 2005). The living, natural playground of the forest serves as a driving force that promotes preschool children's infinite imagination and curiosity (Song, 2009). This is in line with the result of previous research that, as children enjoy direct experience through observation of natural objects, their curiosity leads to continued interest (Oh, 2006). Curiosity is a key intrinsic motivation for active learning and a reason for voluntary participation; thus, it is necessary to sufficiently provide opportunities to stimulate curiosity through nature activities. Second, nature activities in urban parks have positive effects on discovery and statement of the problem, suggestion and application of ideas, and conclusion about problem solving that are sub-factors of preschool children's scientific problem-solving ability. Forest activities are known to improve preschool children's scientific problem-solving ability (Kang, 2013), and nature ac-

Table 11. Differences between pre and post-test scores for creating and applying ideas to problem

\begin{tabular}{cccccc}
\hline Ranks & $\mathrm{n}$ & Mean Rank & Sum of Ranks & $\mathrm{z}$ & $p$ \\
\hline Negative & $0^{\mathrm{a}}$ & 0.00 & 0.00 & 210.00 & -4.041 \\
Positive & $20^{\mathrm{b}}$ & 10.50 & & \\
Equal & $1^{\mathrm{c}}$ & & & \\
Total & 21 & & & \\
\hline
\end{tabular}

${ }^{\mathrm{a}}$ Post-test scores $<$ Pre-test scores, ${ }^{\mathrm{b}}$ Post-test scores $>$ Pre-test scores, ${ }^{\mathrm{c}}$ Post-test scores $=$ Pre-test scores.

Table 12. Differences between pre and post-test scores for conclusion to problem-solving

\begin{tabular}{cccccc}
\hline Ranks & $\mathrm{n}$ & Mean Rank & Sum of Ranks & $\mathrm{z}$ & \multicolumn{1}{c}{. } \\
\hline Negative & $0^{\mathrm{a}}$ & .00 & .00 & 91.00 & \\
Positive & $13^{\mathrm{b}}$ & 7.00 & & \\
Equal & $8^{\mathrm{c}}$ & & & \\
Total & 21 & & & \\
\hline
\end{tabular}

${ }^{\mathrm{a}}$ Post-test scores $<$ Pre-test scores, ${ }^{\mathrm{b}}$ Post-test scores $>$ Pre-test scores, ${ }^{\mathrm{c}}$ Post-test scores $=$ Pre-test scores. 
tivities also do the same by providing preschool children with fun things to explore and see with a more flexible approach (Shin, 2008) Therefore, nature activities lay the groundwork for problem solving in life through the process of stating and solving science-related problems.

\section{Conclusion}

This study is conducted to determine the effects of nature activities in urban parks on preschool children's curiosity and scientific problem-solving ability. The following conclusions can be drawn based on the results of this study. First, nature activities in urban parks had effects on improving preschool children's curiosity. By sub-factor of curiosity, there were positive effects on preference for unknown and exploratory behavior. Therefore, curiosity is a key intrinsic motivation for active learning and a reason for voluntary participation; thus, it is necessary to sufficiently provide opportunities to stimulate curiosity through nature activities. Second, nature activities in urban parks had effects on preschool children's scientific problem-solving ability. By sub-factor of scientific problem-solving ability, there were positive effects on discovery and statement of the problem, suggestion and application of ideas, and conclusion about problem solving. Nature activities lay the groundwork for problem solving in life through the process of stating and solving science-related problems.

\section{References}

Bento, G. and G. Dias. 2017. The important of outdoor play for young children's healthy development. Porto Biomed. J. 2(5):157-160. https://doi.org/10.1016/j.pbj.2017.03.003

Borowske, K. 2005, April. Curiosity and motivation-to-learn. Proceedings of ACRL 12th National Conference (pp. 346-350). Minneapolis, MN: Association of College \& Research Libraries.

Cho, H.S. 2005. The development and evaluation of a nature friendly program for young child. Korean J. Early Child. Educ. 25(5):343-366.
Cho, H.S. and J.S. Kim. 2013. The effects of everyday life invention activities on creativity, scientific problem solving skills and scientific attitude of young children. Korean J. Early Child. Educ. 33(3):401-422.

Handerson, B.B. and S.G. Moore. 1979. Measuring exploratory behavior in young children: A factor-analytic study. Dev. Psychol. 15(2):113-119. https://doi.org/10.1037/0012-1649.15.2.113

Hwang, H.I., H.E. Lee, and E.M. Go. 2012. Baby examination manual III. Goyang, Korea: Jungminsa.

Kang, Y.S. 2013. The effects of education for environmental pollution prevention through forest experiences on children's nature-friendly attitudes and scientific problem solving ability. J. Korea Acad. Ind. Coop. Soc. 14(4):1604-1611. https://doi.org/10.5762/KAIS.2013.14.4.1604

Kellert, S.R. 2005. Building for life: Design and understanding the human-nature connection. Washington, DC: Island Press.

Kim, E.J. 2010. Diagnosis of problems in early childhood education and exploration for searching for ecological early childhood education. J. Eco Early Child. Educ. Care 9(4):53-82.

Kim, M.K. 2016. The effects of tool-centered comparative observation activities on the scientific inquiry ability and curiosity of young children. Master's thesis, Chung-Ang University, Seoul, Korea.

Kim, S.G. 2013. Constructivist early childhood science education. Seoul, Korea: Seohyunsa.

Kim, Y.S. and J.J. Kim. 2004. A survey of early childhood teachers' science education and their need for educational support. Early Child. Edu. Res. Review 8(2):157-181. Retrieved from http://www.eceteacher.com

Ko, S.A. and H.S. Cho. 2015. The effects of science education program based on outdoor play for young children on young children's creativity, curiosity and scientific process skills. Early Child. Educ. Res. Rev. 19(6):447-469. Retrieved from http://www.eceteacher.com

Kwak, H.L. 2015. Constructivist early childhood education teaching and learning. Goyang, Korea: Kongdongche.

Lee, N.H. 2001. The effects of science inquiry learning on young children's scientific process skills and curiosity. Master's thesis, Sungkyunkwan University, 
Seoul, Korea.

McReynolds, P., M. Acker, and C. Pietila. 1961. Relation of object curiosity to psychological adjustment in children. Child Dev. 32(2):393-400. https://doi.org/10. 2307/1125953

Ministry of Education, Science and Technology. 2013. Contents of Nuri-Curriculum by age: For 3-5 years old. Seoul, Korea: Author [Ministry of Education].

Moon, E.J. 2000. The effect of unfolding type of small-group science activity on young children's creativity and problem-solving ability. Master's thesis, Korea National University of Education, Cheongju, Korea.

Oh, Y.R. 2006. A study on the effect of the observation of natural things and representation activity on 5-year-old children's scientific concepts, process skills and sttitude. Master's thesis, Chung-Ang University, Seoul, Korea.

Seo, H.J. 2018. Development of early childhood science program for sustainable development. Doctoral dissertation, Korea National University of Education, Cheongju, Korea.

Shin, L.H. 2008. The nature of experiencing woodwork with regard to children' scientific problem-solving abilities and scientific attitude effects. Master's thesis, Chonbuk National University, Jeonju, Korea.
Smock, C.D. and B.G. Holt. 1962. Children's reaction to novelty: An experimental study of "curiosity motivation”. Child Dev. 33(3):631-642.

Song, E.J. 2009. The effects of forest experience activities on young children's spatial abilities. Master's thesis, Seoul National University of Education, Seoul, Korea.

Tegano, D.W., J.K. Sawyers, and J.D. Morans, III. 1989. Problem-finding and solving in play: The teacher's role. Child. Educ. 66(2):92-97. https://doi.org/10.1080/0009 4056.1989.10522492

Wells, N.M. 2000. At home with nature: Effects of "greenness" on children's cognitive functioning. Environ. Behav. 32(6):775-795. https://doi.org/10.1177/001391 60021972793

Yildirim, G. and G. Özyilmaz Akamca. 2017. The effect of outdoor learning activities on the development of preschool children. S. Af. J. Educ. 37(2):1-10.

Yoon, K.Y. 2008. The effects of the science activities through the nature observation on young children's scientific process skills and nature-friendly attitudes. Master's thesis, Dongguk University, Seoul, Korea.

Yoon, M.S. 2012. The effects of science activities for enhancing creativity on young children's curiosity scientific problem-solving ability. Master's thesis, Korea National University of Education, Cheongju, Korea. 